\title{
EXTREME POINT RAINFALL TEMPORAL SCALING: A LONG TERM (1805-2014) REGIONAL AND SEASONAL ANALYSIS IN SPAIN
}

\author{
Extreme point rainfall temporal scaling in Spain
}

\section{Sergi Gonzalez ${ }^{1,2 *}$, Joan Bech ${ }^{1}$}

${ }^{1}$ Department of Applied Physics - Meteorology, University of Barcelona, Spain

${ }^{2}$ Meteorological Surveillance and Forecasting Group, DT Catalonia, Agencia Estatal de Meteorología

(AEMET), Barcelona, Spain

Correspondence to: S. Gonzalez, DT Catalonia, AEMET. C/ Arquitecte Sert, 1, E-08003, Barcelona, Spain. Email: sgonzalezh@aemet.es

\section{Abstract}

This paper presents a regional and seasonal study of extreme point rainfall scaling from 10 minutes to 2 years. To do this, the highest point-based rainfall list for different temporal periods spanning from 10 minutes to 2 years was calculated from the Spanish Meteorological Service (AEMET) precipitation databases with more than 11000 rain gauge stations, with the longest series ranging from 1805 to 2014 (209 years). This list constitutes the register of single station largest amounts of precipitation in Spain ever recorded for selected periods, including for example the values for $2 \mathrm{~h}(193 \mathrm{~mm}), 24 \mathrm{~h}(817 \mathrm{~mm})$ or 1 year $(5503 \mathrm{~mm})$. Rainfall extremes for 10 minute periods are evenly distributed in coastal and inland areas. Daily precipitation extremes are mostly concentrated over the Mediterranean coast while from durations from one month to two years, extremes are located in southern and northwest Spain. Extreme data obtained were compared with existing worldwide rainfall records for equivalent periods. Results indicate that Spanish extreme rainfall scaling relating $\mathrm{R}$ depth (in $\mathrm{mm}$ ) vs $\mathrm{D}$ duration (in minutes) may be expressed as a potential law $R=21.8 \mathrm{D}^{0.422}\left(\mathrm{R}=43.6 \mathrm{D}^{0.507}\right.$ for worldwide data). Further analysis stratifying results by season and region show that seasonal scaling has more variability than regional scaling. The methodology described can be readily applied to other regions for which detailed rainfall databases exist. Applications of the results include using the scaling found as a reference for classification of 
heavy precipitation events for temporal scales.

Keywords: extreme precipitation, rainfall depth duration scaling, rainfall ranking, heavy precipitation event, Spain

\section{Introduction}

The study of extreme rainfall point records, i.e. absolute maximum precipitation amounts registered at specific stations, has been a relevant research topic for decades given the implications for water cycle management purposes, meteorological processes involved, hydraulic design, flood early warning systems or climatological analysis, more recently, in a context of climate change. Wussow (1922) studied point heavy rainfall events in Germany for aggregation periods between 30 minutes and $24 \mathrm{~h}$ and found that maximum rainfall records $R$, expressed in $\mathrm{mm}$, increased with duration $D$, in minutes, according to $R=\sqrt{20 D}$, i.e. showing a power law dependence between depth and duration with exponent 0.5. Jennings (1950) presented a collection of the world greatest observed point rainfalls for 39 different time periods spanning from 1 minute to 2 years, plotting them in a log-log graph which showed an approximately linear dependence, consistent with a power law behaviour. Paulhus (1965) updated the record list of Jennings with some new values and, considering 29 records, fitted an envelope curve to the data using a power law, obtaining 0.475 for the exponent. This relationship has been quoted as Jenning's scaling law in some studies such as Galmarini et al. (2004), Zhang et. al. (2013a,b) or Breña-Naranjo et al. (2014) and represents the maximum rainfall amount possible in a given time period limited by physical factors such as moisture availability, atmospheric instability, large scale dynamics o orographic factors. Substantial efforts have been devoted to study this scaling law, for example using multifractal theory (Hubert et al., 1993), statistical autocorrelation (Galmarini et al., 2004) or stochastic truncated autoregressive models (Zhang et. al., 2013b). In a framework of physical complex systems, the precipitation process has been described formally as a self-organized critical process, like other natural phenomena such as earthquakes (Peters et al., 2002; Peters \& Christensen, 2002). 
With a similar approach Moncho et al. (2009), Monjo (2016) and Monjo \& Martin-Vide (2016) employed a dimensionless $n$-index, which was the exponent of the power function fitting the greatest rainfall for different time periods at a given location to analyse individual rain events. This index has been tested with rain gauges around the world showing again a fractal behaviour as reported by Monjo (2016) and Monjo \& Martin-Vide (2016).

Many other studies regarding extreme precipitation have been performed based on the analysis of long term rainfall data and the development of depth vs duration relations which allowed deriving probable depth amounts for specific return periods - see for example Bell (1969) or other approaches based on scaling properties of the rainfall at different scales such as those described in Burlando \& Rosso (1996), Casas et al. (2010) or Pérez-Zanón et al., (2015).

The objectives of this paper are 1). to determine absolute extreme point-rainfall records in Spain for different durations, 2). to examine possible power law scalings of the extreme values found and, 3). to analyze subsequent regional and seasonal variability. To achieve these targets a large data set of more than 11000 rain gauge stations ranging from 1805 to 2014 has been used, which is described in detail in Section 2. In Section 3, we discuss the extreme values of Spain for different scales from 10 minutes to 2 years. The extreme depth duration scaling for Spain is characterized in Section 4, comparing it with world records and analyzing seasonal and regional variability. Finally, we present a summary of findings and conclusions in Section 5.

\section{Data sources and extreme rainfall records}

\subsection{Spanish extreme precipitation data}

In order to obtain precipitation extreme amounts with different durations we did a comprehensive survey of all Spanish Meteorological Service (AEMET) precipitation databases that cover all temporal ranges and the entire Spanish territory, including mainland Iberian Peninsula, Balearic Islands and subtropical Canary Islands (Figure 1). The most important features of each of the four databases used are listed in Table 1. Data passed through several quality controls by AEMET Climatological Department (AEMET, 2009) and each checked record was flagged with two possible status: valid and suspicious (not valid records were not available in the databases 
used). From these two sets, only valid data were used in this analysis.

A list of maximum rainfall data for different time periods spanning from 10 minutes to 2 years was calculated from AEMET databases. The time periods selected are based on those given by Galmarini et al. (2004) and NWS (2014). The rainfall extreme values were calculated using rolling sums applied over moving windows. Note that records in a given time period may include non-rainfall data, $i$. e. extreme records obtained do not necessarily imply continuous precipitation for the period considered. Maximum rainfall extremes calculated with this method are listed in Table 2. We provide as well, the ranking of the 10 highest point-based precipitation for several durations in Table S1.

From 10 minutes to 1 hour, we used a daily database generated by 10 -minutely database with the maximum amounts of precipitation in 10, 20, 30 and 60 minutes for each day. From 2 hours to 18 hours we used an hourly database. We computed maximum extremes for several durations using rolling sums. Hourly database is derived from the 10-minutely database so, time series contained have the same temporal coverage. Both, 10-minutely and hourly databases, started in 1980 with a marginal number of rain gauge stations. Since then, the number of stations have been steadily increasing. By now there are more than 900 10-minutely automatic rain gauges distributed around Spain starting the oldest one in 1973. This is a relative small number if compared with the number of stations in the following database

From 1 day to 31 days we used the daily (from 07:00 to 07:00 UTC) database detailed by Ramis et al. (2013) and from 2 months to 2 years we used a monthly database created from the daily data. We performed the rolling sums of the whole database in order to obtain the maximum amounts for different durations. These networks have more rain gauges (more than 9000 nowadays) and are much longer than sub-daily ones (the oldest one starting in early XIX century). Consequently, there is a large discontinuity between sub-daily and supra-daily temporal coverage. As a result of this discontinuity, we detected that greatest rainfall recorded in 9,12 and 18 hours by sub-daily database are lower than the minimum possible in these durations estimated considering 
stationary rainfall rate in the greatest precipitation ever registered in 1 day ( $817 \mathrm{~mm}$ at Oliva), so we select the esimated values as the greatest values. For example, the proportional part of that event corresponding to 12 hours is $408.5 \mathrm{~mm}$, exceeding the maximum amount found in the hourly database, that is $314.6 \mathrm{~mm}$.

We grouped rain gauges stations in four domains showed in Figure 2. Mediterranean domain (MED) takes the pragmatic definition of Romero et al. (1998) and includes all stations in administrative regions which border the Mediterranean Sea. Similarly, Atlantic domain (ATL) has been chosen so that rain gauges located in the regions to the Atlantic. The remaining regions into peninsular Spain were classified as Continental rain gauges $(\mathrm{CON})$ and none of them is close to the sea. Stations that cover Canary Islands are classified as Subtropical rain gauges (SBT).

\subsection{World extreme precipitation data}

We obtained the world extreme point-based rainfall measurement from NOAA National Weather Service (NWS, 2014). These measurements represent the current extreme rainfall ever recorded for each scale. NOAA National Weather Service first retrieved the data from WMO (1994) and nowadays maintains the most updated extreme rainfall data available. The latest update were several records broken between the 3 to 9 days time spans, registered at Commerson crater in Reunion Island when the Tropical Cyclone Gamede crossed trough the island in 2007 (Quetelard, 2009). Most of the extremes are listed in Table 2. This list has been used in other studies related with the global extreme rainfalls (e.g. Galmarini et al., 2004 and Zhang et. al., 2013a).

\section{Discussion of extreme rainfall values}

Specific values of Spanish rainfall extremes (SE), and their corresponding World extremes (WE), as well as their proportion (\%) are listed in Table 2. This table is obtained after examining the AEMET rainfall databases as described in Section 2. In this section are discussed the values obtained considering two groups: 10 minutes to 18 hours and 24 hours to 2 years. This separation corresponds approximately to microscale and mesoscale (10 minutes to 18 hours) and to synoptic and planetary scales ( 24 hours to 2 years) according to the classical classification given by Orlanski (1975). 


\subsection{From $10 \mathrm{~min}$ to $18 \mathrm{~h}$}

Total point-based rainfall is the product of the precipitation rate (which depends on the air vertical motion, moisture supply and precipitation efficiency) and event duration (Doswell et al., 1996). As noted Trenberth et al. (2003), moisture availability from the atmosphere is very limited since the precipitable water in midlatitudes hardly exceeds $40 \mathrm{~mm}$, and precipitation efficiency is rarely greater than 70\%, being sometimes even lower (Ferrier et al., 1996; Anip and Market, 2007). So, in an extreme precipitation event, part of the moisture supply typically must come from moisture advection, and the other part through surface evaporation. The recycling ratio shows the relation between these two sources being higher as much rainfall comes from local surface evaporation. Recycling ratio is greater in summer than in winter according to Trenberth et al. (1999b).

At very short scales, typically from a few minutes to one hour, most of the local atmospheric moisture must be released to produce extreme precipitation events typically associated to deep moist convection. Such events need a large amount of precipitable water over a wide area and mechanisms that trigger strong vertical air motions like those present in organized convective storms. This kind of process can occur over most of Spain as well as other tropical and midlatitude places (see Table 1), as discussed Galmarini et al. (2004). Therefore, it is reasonable to think that Spain has the same potential to develop, for short temporal periods of the order of few minutes, extreme rainfalls as great as any other country that holds short scale precipitation records such as Romania or Germany - $206 \mathrm{~mm}$ in 20 minutes and $126 \mathrm{~mm}$ in 8 minutes, respectively, according to NWS (2014). The probability of capturing those events depends on the spatial and temporal density of observations and the temporal length of the datasets. For these reasons, and because of the temporal and spatial limitations of the 10-minutely database explained in Section 2, SE at those scales might be underestimated compared to longer scales duration present in daily and monthly databases, and consequently short scales extremes may quickly increase with a wider and longer database. 
For scales between some tens of minutes until a few hours, besides organized air vertical currents to maintain the precipitation intensity, it is needed a constant transport of moisture from nearest sources for a few hours or even from further sources for a few days. This situation may be exemplified by the event \#5, that correspond with the HyMEX Intensive Observation Period 8 (IOP8) (Jansà et al. 2014). This event has been well studied (Röhner et al. 2016; Khodayar et al. 2016) and it is demonstrated the importance of the feeding moisture (Röhner et al. 2016). Furthermore, it has been observed for some heavy precipitation events (HPEs) in the Western Mediterranean region that moisture can be transported from the Mediterranean Sea as well as from further sources such as the North Atlantic Ocean (Duffourg and Ducrocq, 2011; Trapero et al., 2013; Röhner et al. 2016).

It seems likely that extreme rainfall records in Spain obtained for periods until 18 hours may be underestimated compared to longer periods, especially from 9 to 18 hours, as illustrated by the fact that the records obtained for those periods were estimated from the maximum 24 hours case (817 mm, event \#6) as explained in Section 2.

\subsection{From 1 day to 2 years}

So far we discussed sub-daily data scales that seems to be underestimated since the spatial and temporal resolution is limited. For scales over a day, this argument is not valid since our database has more than 10000 rain gauges that last almost two centuries for the longer station series. Highest SE compared with WE is for 1-day duration, when at 3 November 1987 was recorded in Oliva (Valencia) 817 mm (episode \#6) (Riosalido et al., 1988; Romero et al. 2000), which represents a $44.8 \%$ of the 1-day WR.

Recently, it has been published a ranking of daily and multi-day precipitation extreme events for Iberian Peninsula (Ramos et al., 2014 and Ramos et al., 2016, hereafter Ram46) using a high-resolution $\left(0.2^{\circ}\right)$ gridded daily database, considering both the intensity of the grid point and the area affected. It is remarkable the difference between point-based extreme precipitations and those in Ram46. For example, the highest precipitation for 1 day in Oliva corresponds to the $309^{\text {th }}$ 
extreme event in Ram46. Similarly, the extreme precipitation records of episode \#7 (the most extreme point-based precipitation for periods spanning between 2 and 5 days) do not appear in any of the top 100 events for 3-day and 5-day period. The episode \#9 (the most extreme point-based precipitation for time spans between 7 and 20 days) appear as the $24^{\text {th }}$ and the $20^{\text {th }}$ most extreme events for 7-day and 10-day period respectively. Those examples show that the point-based extreme precipitation events generally do not correspond to events affecting large areas, especially for shorter time durations.

From 3 days to 7 days there is a noteworthy period where precipitation does not increase due to the exceptional nature of one single event (event \#7, $978 \mathrm{~mm}$ in 3 days); this episode is not overtaken until the 6-day period of subtropical rainfall in Canary Islands exceeds it. Events \#2 and \#3 occurred in the coastal region of Valencia (E Spain), which has the highest rainfall variability in Spain (Martin-Vide, 2004) and relatively few precipitation days per year compared with other areas in the Iberian Peninsula (IM-AEMET, 2011). Interestingly, from periods of 7-day onward, the extreme precipitation regions move to Grazalema mountain range (S Spain) and Galicia (NW Spain), two of the wettest regions in Spain.

For scales longer than a few days it is not needed a large amount of moisture transport in a short time but a constant input of moisture along the time with many consecutive days (Casanueva et al. 2014). This is why at longer scales the geographical distribution changes from the Mediterranean to the Atlantic region of Galicia (from event \#11 to \#13), where westerlies predominate advecting moist air masses regularly. According to results in Table 2, the percentages of SE vs. WE vary from $44.8 \%$ (at 24 hours) to $17.5 \%$ (for 1, 3 and 4 months). Remarkably from 4 day periods, percentages do not exceed $23 \%$. A possible explanation for this, is that moisture at middle latitudes is distributed as transient, relatively narrow areas or strings known as atmospheric rivers (Zhu and Neweel, 1998), and presence or absence of these moisture belts precipitating over a point, acts as a limiting factor for large scale extreme rainfall. Hence, in mid-latitudes moisture input is irregular compared with that in the WE in the tropics, where large scale tropical circulations 
as the monsoons over the Indian subcontinent provides a constant input of moisture. Therefore, SE heavy rains for several days or months cannot last long, being SE around 20\% with respect to WE from 4 days onwards. This approximate relation holds at least until a duration of two years.

\section{Extreme depth duration scaling}

\subsection{Data fit and upper envelope}

Figure 3 shows a log-log plot of rainfall depth $P$ [mm] vs. duration $D$ [minutes] of Spanish rainfall extremes (SE) and the world extremes (WE). For both datasets, we computed the fitting line $\log (P)=\mathrm{a}+\mathrm{b} \log (D)$ (bold line in Figure 3) using least squares linear regression, which in power law format may be expressed as $\mathrm{R}=43.6 \mathrm{D}^{0.507}\left(\mathrm{r}^{2}=0.958\right)$ for $\mathrm{WE}$ and as $\mathrm{R}=21.8 \mathrm{D}^{0.422}\left(\mathrm{r}^{2}=\right.$ 0.978 ) for SE where $R$ is rainfall depth in mm and $D$ is duration in minutes.

Following the approach by Paulhus (1965), the upper envelope (dashed line) was plotted too, finding a parallel line to the data fit (i.e. with the same slope $b$ ) which was moved upwards to reach the furthest depth duration point so all rainfall record amounts are equal or below the envelope line. Specifically, from all possible data points $\left(D_{i}, P_{i}\right)$, the furthest point $\left(D_{\text {sup }}, P_{\text {sup }}\right)$ to the fit line was determined by finding the point with the maximum distance:

$$
\left(D_{\text {sup }}, P_{\text {sup }}\right)=\left\{\left(D_{i}, P_{i}\right) \mid \operatorname{Max}\left\{\frac{\left|b \cdot D_{i}-P_{i}+a\right|}{\sqrt{b^{2}+1}}\right\}\right\}
$$

We get the envelope line $\log (P)=a_{\text {env }}+\mathrm{b} \log (D)$, obtaining a new intercept $a_{\text {env }}$ calculated as:

$$
a_{\text {env }}=b *\left(-D_{\text {sup }}\right)+P_{\text {sup }}
$$

Using this method and the most updated data, the WE envelope may be expressed as $\mathrm{R}=$ $60.5 \mathrm{D}^{0.507}$ and the SR envelope as $\mathrm{R}=39.3 \mathrm{D}^{0.422}$.

In a first approximation, both WE and SE exhibit a close power-law scaling. A power-law goodness-of-fit test (Gaudoin et al., 2003) shows that both data sets are compatible with a powerlaw scaling. In both cases, only few rain events contribute to most of the registered extremes. The locations of SE episodes are showed at Figure 1. It is remarkable that all SE are located near the sea, even for large time spans. Locations are clustered in the Mediterranean and Canary Islands for 
mid and short scales and near the Galician coast for longer scales. It is also worth to notice that except Sineu (Balearic Islands, extreme \#2 in Table 1) and Huercal-Overa (Almeria, extreme \#5), all other maximum amounts are located in areas of complex terrain. This suggests that both, sea proximity and a complex orography (the last one, especially for scales longer than 6 hours) are critical ingredients to develop extreme rainfall amounts. This is consistent with previous climatological studies such as Romero et al. (1998) and Ramis et al. (2013).

As discussed above, extreme rainfalls shorter than a day might be underestimated and may disturb the scaling. However, we have seen that the event fitting line is compatible with a powerlaw scaling. This means that some discontinuities have a very little effect in the scaling goodnessof-fit. Therefore, we can assume that the discussion of the extremes precipitation may be hardly affected by this discontinuity. This applies too for the discussion from here on.

\subsection{Regional variability}

Figure 4 shows the amount of the most extreme precipitation for each location at different scales, while Figure 5a shows the scaling of the greatest rainfalls for each domain we divided Spanish territory in Section 2. From 10 minutes to 3 hours absolute rainfall extremes for each station at short scales are evenly distributed in Spain (Figure $4 \mathrm{a}$ and b). In fact, among the records for these time spans, there are absolute extremes (i.e. the maximum for a given time duration) from three different regions (MED, ATL and SBT). This agrees with Galmarini et al. (2004) statement that short scales extremes can occur indistinctly both in mid-latitudes and tropics.

For scales from 4 hours to 5 days, extreme precipitation in MED clearly dominates over the other regions. MED region has all the ingredients that permit to have the heaviest rainfalls at daily scales: a warm sea that supplies moisture and potential instability that may release all this moisture, small scale shallow cyclones that can mobilize the moisture and provide constant transport to the storm (Jansà, 1997), and complex terrain that can locally lift the moisture, concentrating moisture and rainfall in a small territory.

Daily variability has been studied by Martín-Vide (2004) who elaborated a Concentration 
Index (CI) that evaluated the contribution of the days with greatest rainfall to the total amount. SE distribution for 1 day (Figure 4c) fits pretty well with the daily CI distribution defined by MartinVide (2004) that already divided peninsular Spain into two regions, the Mediterranean façade and the rest of the country. The main difference between CI and SE distribution is that the last one is more concentrated near the coast.

As already commented by Ramis et al. (2013), when they characterized the daily greatest point-based precipitations in mainland Spain, most of the extreme daily precipitations (over 500 $\mathrm{mm})$ occur near the Mediterranean coastline except one single event at the Pyrenees $(700.5 \mathrm{~mm}$ at Benasque station in 1923). This point is the only one that exceeds $500 \mathrm{~mm}$ outside the MED region and the event was likely influenced by orographic factors.

For scales longer than a month, SE tend to concentrate at mountain ranges of the western façade (Figure $4 d$ and e). The longer the time span the larger are the amounts near the Atlantic compared with the Mediterranean region. This may be explained because the Atlantic Ocean and, specially, the atmospheric rivers provides a constant moisture supply in ATL region that can be released by mechanical ascent favoured by the mountains. No other place in Spain has such a constant input of moisture during the whole year (Casanueva et al. 2014) and therefore, a succession of fronts during several months may produce a considerable amount of rainfall.

Notice that although the five regions are climatically different, they do not show large differences in the scaling, especially in the exponent that is comprised between 0.39 and 0.44 . Since rainfall at short scales is not much different between regions, exponent is well related with the wetness of the region and the variability of the moisture transport rate through the year. As we explained above, ATL has a constant moisture input (Fernández et al., 2003, Gimeno et al., 2010) that implies longer rainy periods for large scales and therefore a greater exponent. On the contrary, SBT region has a clear seasonal drought that produces lower extremes at large scales, and therefore a lower exponent. MED and INT regions have an intermediate exponent close to the average Spanish exponent. These results extend to most extreme rainfalls, those obtained by Meseguer-Ruiz 
et al. (2016) who linked the fractal dimension of the precipitation to the regular recurrence of precipitation through the scales. Regional variability comes out when we diminish the area of the regions using Spanish provinces (see Appendix 1). For these small regions, very dry provinces of southeastern Spain as Murcia or Almeria present a low exponent ( 0.3) while the wetter provinces located in the northwest of Spain as Ourense or A Coruña have a higher index ( 0.5).

\subsection{Seasonal variability}

Figure $5 b$ shows depth vs. duration scaling plot in Spain for each season. Differences in the exponent between seasons are larger than between regions. In winter, moisture content in the atmosphere is relatively small so, when it is released and produces heavy rainfall, greatest values at short scales are typically lower than in warm season convective events. Nevertheless, on winter, moisture fluxes in Spain can be more stable during all season since polar jet circulates at lower latitudes. This means that in comparison, greatest rainfalls at large temporal scales are higher than at short scales and therefore exponent values become high, close to 0.5 .

By contrast, moisture content of the atmosphere may reach maximum values in summer, and elevated instability is able to release it in a few hours, especially near the Mediterranean Sea that offers a great source of moisture. For this reason, it is not difficult to find events where more than $100 \mathrm{~mm}$ are registered in one or few hours. However, during the warm season transport of moisture is more intermittent and Canary and Iberian summer climate is characterized by high pressure systems that do not permit to have large rainfalls over long temporal scales (Esteban et al., 2006). This explains the lower exponent (0.3) that characterizes summer for Spain.

Spring and autumn have intermedium exponents (0.4) and are seasons of transition between the winter and summer regimes. Even so, most of the extremes in almost all scales occur in autumn.

In Table 3, we examined seasonal differences for each region. Results show that these features (lower exponents in summer and larger exponents in winter) are common for all regions, even those ones with very different climates as ATL and SBT. 


\section{Summary and concluding remarks}

After a comprehensive analysis of the Spanish precipitation databases, this paper has documented the most extreme rainfall amounts in Spain for a large range of temporal scales. Despite there are studies documenting sets of extreme rainfall events for a given country or area at selected time periods (see for example Hand et al 2004, Cerveny et al 2007 or Shein et al 2013), as far as the authors know, this is the most complete survey of absolute extreme rainfalls made in a country providing records from 10 minutes to 2 years. We complemented this data with a ranking of the 10th highest rainfall for each time span in Spain and the highest precipitation for each domain and province as well.

For short scales less than 3 hours, extreme rainfall events are widespread distributed through Spain while for scales from 4 hours to 20 days rainfalls are concentrated in the Mediterranean and sometimes in Canary Islands. For scales larger than a month rainfalls are mainly concentrated at the Atlantic façade, where Atlantic westerlies provides a constant moisture input.

Power scaling of the extreme rainfalls in Spain has been compared with the extreme rainfalls in the World. This relation largely varies with the scale, from $45 \%$ in 1 day to $18 \%$ at large scales. Both data sets are compatible with a scaling law, even though Spanish data below a day seems to be clearly underestimated with the amount of data available.

We characterized the spatial distribution and the regional and seasonal scaling of extreme precipitation showing that main features that characterize the scaling and the extremes rainfalls in Spain are 1) moisture content of the atmosphere for short scales, 2) constant moisture transport supply for larger scales, 3) orography and, 4) proximity to the sea.

For different regions, the scaling is characterized for larger scales more than shorter scales, since the extreme precipitation for shorter scales is similar for all regions. Nevertheless, the scaling factor does not change so much between regions. Conversely, scaling is very different between seasons, being the scaling factor much greater for winter than for summer. Our results qualitatively agree with other indices calculated for the Iberian Peninsula as CI (Martín-Vide, 2004) or fractal dimension (Meseguer-Ruiz et al. 2016). 
The resulting lists of precipitation extremes may be used as a reference framework to characterize the amount of precipitation of HPEs in function of its distance to the record, thus providing a classification method useful both for case studies or more exhaustive climatological analysis.

\section{Acknowledgments}

This work was performed under the framework of the Hydrological Mediterranean Experiment (HyMeX) programme and was partially supported by the Spanish project CGL201565627-C3-2-R (MINECO/FEDER) and the Water Research Institute (IdRA) of the University of Barcelona. The authors thank the support of Cesar Rodríguez Ballesteros from AEMET climatological department for his help in retrieving the records from the AEMET data bases. 


\section{Appendix}

Table A1. Extreme rainfall scaling fit for each Spanish province, $R=a D^{b}$, with $R$ in $\mathrm{mm}$ and $D$ in minutes, adjusted with records from 10 minutes to 2 years, showing the parameters $a$ and $b$ and correlation coefficient.

\begin{tabular}{|c|c|c|c|}
\hline PROVINCE & $\mathbf{a}$ & b & $\mathbf{r}^{2}$ \\
\hline BARCELONA & 14.802 & 0.380 & 0.978 \\
\hline TARRAGONA & 21.884 & 0.331 & 0.971 \\
\hline GIRONA & 12.119 & 0.429 & 0.981 \\
\hline LLEIDA & 10.844 & 0.407 & 0.982 \\
\hline CANTABRIA & 11.487 & 0.414 & 0.982 \\
\hline CORDOBA & 21.443 & 0.339 & 0.971 \\
\hline HUELVA & 14.783 & 0.382 & 0.978 \\
\hline SEVILLA & 9.896 & 0.431 & 0.984 \\
\hline JAEN & 5.099 & 0.489 & 0.991 \\
\hline GRANADA & 7.961 & 0.469 & 0.986 \\
\hline ALMERIA & 31.088 & 0.313 & 0.963 \\
\hline CADIZ & 10.018 & 0.484 & 0.987 \\
\hline MALAGA & 19.041 & 0.407 & 0.978 \\
\hline ALICANTE & 24.895 & 0.368 & 0.972 \\
\hline VALENCIA & 26.845 & 0.349 & 0.969 \\
\hline CASTELLON & 17.995 & 0.364 & 0.975 \\
\hline TERUEL & 9.008 & 0.420 & 0.983 \\
\hline HUESCA & 10.399 & 0.456 & 0.984 \\
\hline ZARAGOZA & 9.175 & 0.392 & 0.983 \\
\hline GUADALAJARA & 5.694 & 0.434 & 0.988 \\
\hline CUENCA & 9.018 & 0.417 & 0.984 \\
\hline TOLEDO & 8.976 & 0.410 & 0.985 \\
\hline ALBACETE & 14.486 & 0.365 & 0.977 \\
\hline CIUDAD REAL & 4.713 & 0.453 & 0.991 \\
\hline LEON & 6.045 & 0.496 & 0.990 \\
\hline BURGOS & 8.341 & 0.440 & 0.986 \\
\hline VALLADOLID & 6.281 & 0.398 & 0.986 \\
\hline PALENCIA & 6.061 & 0.459 & 0.989 \\
\hline ZAMORA & 4.122 & 0.516 & 0.993 \\
\hline SORIA & 7.987 & 0.414 & 0.985 \\
\hline SEGOVIA & 6.287 & 0.425 & 0.988 \\
\hline AVILA & 6.973 & 0.495 & 0.989 \\
\hline SALAMANCA & 10.007 & 0.446 & 0.984 \\
\hline LUGO & 5.986 & 0.497 & 0.990 \\
\hline PONTEVEDRA & 6.699 & 0.496 & 0.990 \\
\hline A CORUNA & 6.517 & 0.511 & 0.990 \\
\hline OURENSE & 5.151 & 0.525 & 0.992 \\
\hline CACERES & 6.447 & 0.488 & 0.990 \\
\hline BADAJOZ & 8.622 & 0.410 & 0.985 \\
\hline NAVARRA & 9.694 & 0.445 & 0.985 \\
\hline GIPUZKOA & 18.090 & 0.382 & 0.976 \\
\hline BIZKAIA & 13.814 & 0.385 & 0.979 \\
\hline ARABA/ALAVA & 6.995 & 0.426 & 0.987 \\
\hline ASTURIAS & 7.836 & 0.455 & 0.987 \\
\hline MURCIA & 29.560 & 0.310 & 0.966 \\
\hline MADRID & 9.616 & 0.410 & 0.984 \\
\hline LA RIOJA & 7.297 & 0.428 & 0.985 \\
\hline BALEARES & 18.964 & 0.404 & 0.978 \\
\hline $\begin{array}{l}\text { LAS PALMAS } \\
\text { SANTA CRUZ DE }\end{array}$ & 13.552 & 0.409 & 0.980 \\
\hline TENERIFE & 23.002 & 0.392 & 0.975 \\
\hline
\end{tabular}




\section{Supporting Information}

This paper is complemented with supporting information listing the 10 highest point-based rainfall values recorded for 38 selected time periods in Spain from AEMET rain-gauge databases. Table S1 contains, for each time period, the following items: CODE (AEMET station code), STATION NAME (Name of the station), CMT (Three letter code of the AEMET regional office in charge of the station), PROVINCE (Spanish administrative province of the station), DATE (Date of the event or initial date for periods longer than 24 hours). 


\section{References}

AEMET. 2009. Descripción de las tablas que componen la base de datos climatológica (ORACLE).

[In Spanish]. Servicio de Banco Nacional de Datos Climatológicos, AEMET, Madrid. Updated June 2016.

Anip MHM, Market PS. 2007. Dominant factors influencing precipitation efficiency in a continental mid-latitude location. Tellus A 59: 122-126. doi: 10.1111/j.160000870.2006.00208x

Bell F. C. 1969. Generalized rainfall-duration-frequency relationships. Journal of Hydraulics division 95: 311-328.

Breña-Naranjo JA, Pedrozo-Acuña A, Rico-Ramirez MA. 2015. World's greatest raifall intensities observed by satellites. Atmospheric Science Letters 16: 420-424. doi: 10.1002/as12.546.

Burlando P, Rosso R. 1996. Scaling and multiscaling models of depth-duration-frequency curves for storm precipitation. Journal of Hydrology 187: 45-65. doi: 10.1016/S00221694(96)03086-7.

Casanueva A, Rodríguez-Puebla C, Frías MD, González-Reviriego N. 2014. Variability of extreme precipitation over Europe and its relationships with teleconnection patterns. Hydrology and earth system sciences 17: 709-725. doi: 10.5194/hess-18-709-2014.

Casas MC, Rodriguez R, Redaño A. 2010. Analysis of extreme rainfall in Barcelona using a miscroscale rain gauge network. Meteorological Applications 17: 117-123. doi: 10.1002/met.166.

Doswell III CA, Brooks HE, Maddox RA. 1996. Flash Flood Forecasting: An ingredient-based methodology. Weather and Forecasting 11: 560-581. doi: 10.1175/15200434(1996)011<0560:FFFAIB>2.0.CO;2.

Duffourg F, Ducrocq V. 2011. Origin of the moisture feeding the Heavy Precipitating Systems over Southeastern France. Natural Hazards Earth System Science 11: 1163-1178. doi: 
10.5194/nhess-11-1163-2011.

Esteban P, Martín-Vide J, Mases M. 2006. Daily atmospheric circulation catalogue for western Europe using multivariate techniques. International Journal of Climatology 26: 1501-1515. doi: 10.1002/joc.1391.

Fernández J, Sáenz J, Zorita E. 2003. Analysis of wintertime atmospheric moisture transport and its variability over southern Europe in the NCEP Reanalysis. Climate Research 23: 195-215. doi: $10.3354 /$ cr023195.

Ferrier BS, Simpson J, Tao WK. 1996. Factors responsible for precipitation efficiencies in midlatitude and tropical squall simulations. Monthly Weather Review 124: 2100-2125. doi: 10.1175/1520-0493(1996)124<2100:FRFPEI>2.0.CO;2.

Galmarini D, Steyn DG, Ainslie B. 2004. The Scaling Law relating world point-precipitation records to duration. International Journal of Climatology 24: 533-546. doi: 10.1002/joc.1022.

Gaudoin O, Yang B, Xie M. 2003. A simple Goodness-of-Fit test for the Power-Law process, based on the Duane plot. IEEE Transactions On Reliability 52: 69-74. doi: 10.1109/TR.2002.805784.

Gimeno L, Nieto R, Trigo RM, Vicente-Serrano SM, López-Moreno JI. 2010. Where does the Iberian Peninsula moisture comes from? An answer based on a lagrangian approach. Journal of Hydrometeorology 11: 421-436. doi: 10.1175/2009JHM1182.1.

Hand WH, Fox NI, Collier CG. 2004. A study of twentieth-century extreme rainfall events in the United Kingdom with implications for forecasting. Meteorological Applications 11: 15-31. doi: $10.1017 /$ S1350482703001117.

Hubert P, Tessier Y, Lovejoy S, Schertzer D, Schmitt F, Ladoy P, Carbonnel JP, Violette S, Desurosne I. 1993. Multifractals and extreme rainfall events. Geophysical Research Letters 20: 931-934. doi: 10.1029/93GL01245.

IM - AEMET. 2011. Iberian Climate Atlas. Agencia Estatal de Meteorología. Instituto de 
Meteorología de Portugal. 80 p.

Jansà A. 1997. A general view about Mediterranean meteorology: cyclones and hazardous weather. INM/WMO International Symposium on Cyclones and Hazardous Weather in the Mediterranean. Universitat de les Illes Balears y Ministerio de Medio Ambiente. ISN-847632-329-8: 33-42.

Jansà A, Campins J, Picornell MA, Guijarro JA. 2014. Heavy rain and strong wind events over Spain during HyMeX SOP1. Tethys 11: 25-38. doi: 10.3369/tethys.2014.11.03.

Jennings AH. 1950. World Greatest Observed Point Rainfalls. Monthly Weather Review 78: 4-5.

Khodayar S, Raff R, Kalthoff N, Bock O. 2016. Diagnostic study of a hish-precipitation event in the Western Mediterranean: adequacy of current operational networks. Quarterly Journal of the Royal Meteorological Society 142: 72-85. doi: 10.1002/qj.2701.

Martin-Vide J. 2004. Spatial distribution of a daily precipitation concentration index in peninsular Spain. International Journal of Climatology 24: 959-971. doi: 10.1002/joc.1030.

Meseguer-Ruiz O, Olcina J, Sarricolea P, Martin-Vide J. 2016. The temporal fractality of precipitation in mainland Spain and the Balearic Islands and its relation to other precipitation variability indices. International Journal of Climatology. doi: 10.1002/joc.4744

Moncho R, Belda G, Caselles V. 2009. Climatic study of the exponent ' $\mathrm{n}$ ' in IDF curves: application for the Iberian Peninsula. Tethys 6: 3-14. doi: 10.3369/tethys.2009.6.01.

Monjo R, Gaitán E, Pórtoles J, Ribalaygua J, Torres L. 2015. Changes in extreme precipitation over Spain using statistical downscaling of CMIP5 projections. International Journal of Climatology. doi: 10.1002/joc.4380.

Monjo R, Martin-Vide J. 2016. Daily precipitation concentration around the world according to several indices. International Journal of Climatology. doi:10.1002/joc.4596.

Monjo R. 2016. Measure of rainfall time structure using the dimensionless n-index. Climate Research 67: 71-86. doi: 10.3354/cr01359.

NWS. 2014. World record point precipitation measurements. National Weather Service. National 
Oceanic and Atmospheric Administration (NOAA) [on line] Last modified: May 6, 2014.

$\begin{array}{llll}\text { [Consulted: } & \text { Nov. } & 11 & \text { 2015]. }\end{array}$

http://www.nws.noaa.gov/oh/hdsc/record_precip/record_precip_world.html

Orlanski I. 1975. A rational subdivision of scales for atmospheric proceses. Bulletin of the American Meteorological Society 56: 527-530.

Paulhus JLH. 1965. Indian Ocean and Taiwan Rainfalls set New Records. Monthly Weather Review 93: $331-335$.

Pérez-Zanón N, Casas-Castillo MC, Rodríguez-Solà R, Peña JC, Rius A, Solé JG, Redaño A. 2015 Analysis of extreme rainfall in the Ebre Observatory (Spain). Theoretical Applications in Climatology: 1-10. doi: 10.1007/s00704-015-1476-0.

Peters O, Christensen K. 2002. Rain: Relaxations in the sky. Physical Review E 66: 036120-1 036120-9. doi: 10.1103/PhysRevE.66.036120.

Peters O, Hertlein C, Christensen K. 2002. A complexity view of rainfall. Physical Review Letters, 88: 18701-1 - 18701-4. doi: 10.1103/PhysRevLett.88.018701.

Quetelard HP, Bessemoulin P, Cerveny RS, Peterson TC, Burton A, Boodhoo Y. 2009. WorldRecord rainfalls during Tropical Cyclone Gamede. Bulletin of American Meteorological Society 90: 603-608. doi: 10.1175/2008BAMS2660.1.

Ramis C, Homar V, Amengual A, Romero R, Alonso S. 2013. Daily precipitation records over mainland Spain and the Balearic Islands. Natural Hazards Earth System Science 13: 24832491. doi: 10.5194/nhess-13-2483-2013.

Ramos AM, Trigo RM, Liberato MLR. 2014. A ranking of high-resolution daily precipitation extreme events for the Iberian Peninsula. Atmospheric Science Letters doi: 10.1002/asl2.507.

Ramos AM, Trigo RM, Liberato MLR. 2016. Ranking of multi-day extreme precipitation events over the Iberian Peninsula. Internatinal Journal of Climatology. doi: 10.1002/joc.4726.

Riosalido R, Rivera A, Martin F. 1988. Development of a mesoscale convective system in the 
Spanish Mediterranean Area. Procedings 7th Meteosat Scientific Users' Meeting. Madrid. 27-30 Set. 1988. EUM P 04: 375-378.

Romero R, Guijarro JA, Ramis C, Alonso S. 1998. A 30-year (1964-1993) daily rainfall data base for the Spanish Mediterranean regions: first exploratory study. International Journal of Climatology 18: 541-560. doi: 10.1002/(SICI)1097-0088(199804)18:5<541::AIDJOC270>3.0.CO;2-N

Romero R, Doswell CA, Ramis C. 2000. Mesoscale Numerical Study of Two Cases of Long-Lived Quasi-Stationary Convective Systems over Eastern Spain. Monthly Weather Review 128: 3731-3751. doi: 10.1175/1520-0493(2001)129<3731:MNSOTC>2.0.CO;2.

Röhner L, Nerding K, Corsmeier U. 2016. Diagnostic study of a HyMeX heavy precipitation event over Spain by investigation of moisture trajectories. Quarterly Journal of the Royal Meteorological Society 142: 287-297. doi: 10.1002/qj.2825

Shein KA, Todey DP, Akyuz FA, Angel JR, Kearns TM, Zdrojewski JL. 2013. Revisiting the statewide climate extremes for the United States: Evaluating existing extremes, archived data, and new observations. Bulletin of the American Meteorological Society 94: 393-402. doi: 10.1175/BAMS-D-11-00013.1.

Trapero L, Bech J, Duffourg F, Esteban P, Lorente J. 2013. Mesoscale numerical analysis of the historical November 1982 heavy precipitation event over Andorra (Eastern Pyrenees). Natural Hazards Earth System Science 13: 2969-2990. doi: 10.5194/nhess-13-2969-2013

Trenberth KE, Dai A, Ramussen M, Parsons DB. 2003. The changing character of precipitation. Bulletin of American Meteorological Society 84: 1205-1217. doi: 10.1175/BAMS-84-91205.

Trenberth KE. 1999b. Atmospheric Moisture Recycling: Role of Advection and Local Evaporation. $\begin{array}{lllll}\text { Journal of } & \text { Climate } & 12 \text { 10.1175/1520- }\end{array}$ 0442(1999)012<1368:AMRROA>2.0.CO;2

Wussow, G. 1922. Untere Grenzwerte dichter Regenfälle. Meteorologische Zeitschrift 39: 173-178. 
Zhang H, Fraderich K, Blender R, Zhu X. 2013a. Precipitation Extremes in CMIP5 Simulations on Different Time Scales. Journal of Hydrometeorology 14: 923-928. doi: 10.1175/JHM-D-120181.1

Zhang H, Fraderich K, Zhu X, Blender R, Zhang L. 2013b. World Greatest Observed Point Rainfalls: Jennings (1950) Scaling Law. Journal of Hydrometeorology 14: 1952-1957. doi: 10.1175/JHM-D-13-074.1.

Zhu Y, Newell RE. 1998. A proposed algorithm for moistures fluxes from Atmospheric Rivers. Monthly Weather Review 126: 725-735. doi: 10.1175/15200493(1998)126<0725:APAFMF>2.0.CO;2.

WMO. 1994. World Meteorological Organization Guide to Hydrological Practices, 5th ed. WMO 168, Geneva, Switzerland; 402 pp. 
Table 1. Metadata of the four databases used in this study.

\begin{tabular}{lrrrrl} 
Name & $\begin{array}{r}\text { Number of } \\
\text { rain gauges }\end{array}$ & $\begin{array}{r}\text { Serie starting } \\
\text { year }\end{array}$ & $\begin{array}{r}\text { Median of } \\
\text { starting years }\end{array}$ & Number of registers \\
\hline BD10Min & 959 & 1973 & 2006 & 3052131 days \\
BDHour & 959 & 1973 & 2006 & $7,5 \mathrm{E}+07$ hours \\
BDDay & 10681 & 1855 & 1968 & $9,2 \mathrm{E}+07$ days \\
BDMonth & 11063 & 1805 & 1966 & 3183192 months \\
\hline
\end{tabular}

Table 2. Observed point-based rainfall extremes for different temporal durations for the WE and SE. The ratio between each SE with their respective WE is also showed. Each SE has an Id number to relate itself with Figure 2 and 3.

\begin{tabular}{|c|c|c|c|c|c|c|c|}
\hline & \multicolumn{4}{|c|}{ Spanish Extremes } & \multicolumn{2}{|c|}{ World Extremes } & \multirow[b]{2}{*}{$\begin{array}{r}\text { Relation } \\
{[\%]}\end{array}$} \\
\hline Duration & Id & Location & $\begin{array}{r}\text { Depth } \\
{[\mathrm{mm}]}\end{array}$ & Date & Location & $\begin{array}{r}\text { Depth } \\
{[\mathrm{mm}]}\end{array}$ & \\
\hline $10 \mathrm{~min}$ & 1 & Cuevas de Nerja, Malaga & 41,6 & 21 Set 2007 & N/A & N/A & N/A \\
\hline $20 \mathrm{~min}$ & 1 & Cuevas de Nerja, Malaga & 74,2 & 21 Set 2007 & Romania & 206 & 36,0 \\
\hline $30 \mathrm{~min}$ & 2 & Sineu, Baleaic Islands & 87,8 & 12 Oct 2012 & China & 280 & 31,4 \\
\hline $60 \mathrm{~min}$ & 3 & Santa Cruz de Tenerife & 129,9 & 31 Mar 2002 & China & 401 & 32,4 \\
\hline 2 hours & 4 & San Sebastian, Gipuzkoa & 193,0 & 1 Jun 1997 & China & 489 & 39,5 \\
\hline 3 hours & 4 & San Sebastian, Gipuzkoa & 204,7 & 1 Jun 1997 & USA & 724 & 28,3 \\
\hline 4 hours & 5 & Huercal-Overa, Almeria & 216,3 & 28 Sep 2012 & N/A & N/A & N/A \\
\hline 5 hours & 5 & Huercal-Overa, Almeria & 248,3 & 28 Sep 2012 & N/A & N/A & N/A \\
\hline 6 hours & 5 & Huercal-Overa, Almeria & 275,0 & 28 Sep 2012 & China & 840 & 32,7 \\
\hline 9 hours & 6 & Oliva, Valencia & $306,4^{*}$ & 0 Nov 1987 & La Réunion & 1087 & 28,2 \\
\hline 12 hours & 6 & Oliva, Valencia & $408,5^{*}$ & 1 Nov 1987 & N/A & N/A & N/A \\
\hline 18 hours & 6 & Oliva, Valencia & $612,8^{*}$ & 2 Nov 1987 & La Réunon & 1589 & 38,6 \\
\hline 1 day & 6 & Oliva, Valencia & 817,0 & 3 Nov 1987 & La Réunon & 1825 & 44,8 \\
\hline 2 days & 7 & Javea, Alicante & 878,0 & 1-2 Oct 1957 & India & 2493 & 35,2 \\
\hline 3 days & 7 & Javea, Alicante & 978,0 & 1-3 Oct 1957 & La Réunion & 3929 & 24,9 \\
\hline 4 days & 7 & Javea, Alicante & 978,0 & 1-3 Oct 1957 & La Réunion & 4869 & 20,1 \\
\hline 5 days & 7 & Javea, Alicante & 978,0 & 1-3 Oct 1957 & La Réunion & 4979 & 19,6 \\
\hline 6 days & 8 & $\begin{array}{c}\text { Sauces, Santa Cruz de } \\
\text { Tenerife }\end{array}$ & 984,8 & 24-29 Feb 1988 & La Réunion & 5075 & 19,4 \\
\hline 7 days & 9 & Grazalema, Cadiz & 1023,2 & 14-20 Dec 1958 & La Réunion & 5400 & 18,9 \\
\hline 8 days & 9 & Grazalema, Cadiz & 1099,2 & 14-21 Dec 1958 & La Réunion & 5510 & 19,9 \\
\hline 9 days & 9 & Grazalema, Cadiz & 1226,2 & 14-22 Dec 1958 & La Réunion & 5512 & 22,2 \\
\hline 10 days & 9 & Grazalema, Cadiz & 1273,6 & 13-22 Dec 1958 & La Réunion & 5678 & 22,4 \\
\hline 11 days & 9 & Grazalema, Cadiz & 1277,2 & 12-22 Dec 1958 & La Réunion & 5949 & 21,5 \\
\hline 12 days & 9 & Grazalema, Cadiz & 1280,0 & 12-23 Dec 1958 & La Réunion & 5949 & 21,5 \\
\hline 13 days & 9 & Grazalema, Cadiz & 1282,2 & 11-23 Dec 1958 & La Réunion & 6072 & 21,1 \\
\hline 14 days & 9 & Grazalema, Cadiz & 1282,2 & 11-23 Dec 1958 & La Réunion & 6082 & 21,1 \\
\hline 15 days & 9 & Grazalema, Cadiz & 1284,8 & 9-23 Dec 1958 & La Réunion & 6083 & 21,1 \\
\hline 20 days & 9 & Grazalema, Cadiz & 1454,1 & 3-23 Dec 1958 & N/A & NA & N/A \\
\hline 31 days & 10 & Cortes de la Frontera, Malaga & 1674,0 & 18 Nov - 18 Dec 1989 & N/A & N/A & N/A \\
\hline $\begin{array}{r}1 \text { natural } \\
\text { month }\end{array}$ & & $\begin{array}{c}\text { Caldera Taburiente, Santa } \\
\text { Cruz de Tenerife }\end{array}$ & 1626,1 & 1-31 Jan 1979 & India & 9300 & 17,5 \\
\hline 2 months & 10 & Cortes de la Frontera, Malaga & 2420,0 & Dec 1995 - Jan 96 & India & 12767 & 19,0 \\
\hline 3 months & 11 & Casteloais, Ourense & 2866,8 & Nov 1959 - Jan 60 & India & 16369 & 17,5 \\
\hline 4 months & 11 & Casteloais, Ourense & 3269,9 & Nov 1959 - Feb 60 & India & 18738 & 17,5 \\
\hline 5 months & 12 & Casas do Porto, A Coruña & 3835,8 & Nov 2000 - Mar 01 & India & 20412 & 18,8 \\
\hline 6 months & 12 & Casas do Porto, A Coruña & 4176,1 & Oct 2000 - Mar 01 & India & 22454 & 18,6 \\
\hline 9 months & 12 & Casas do Porto, A Coruña & 4680,1 & Aug 2000 - Apr 01 & N/A & N/A & N/A \\
\hline 12 months & 12 & Casas do Porto, A Coruña & 5503,4 & Apr 2000 - Mar 01 & India & 26461 & 20,8 \\
\hline 18 months & 13 & Dodro, A Coruña & 7523,6 & Oct 1984 - Mar 86 & N/A & N/A & N/A \\
\hline 24 months & 11 & Casteloais, Ourense & 8991,5 & Feb 1958 - Jan 60 & India & 40768 & 22,1 \\
\hline
\end{tabular}


Table 3. Depth - duration scaling properties for each season and geographical domain.

\begin{tabular}{c|rrr|rrr|rrr|rrr} 
& \multicolumn{3}{|c|}{ DJF } & \multicolumn{3}{|c|}{ MAM } & \multicolumn{3}{|c}{ JJA } & \multicolumn{3}{|c}{ SON } \\
& $\mathbf{a}$ & $\mathbf{b}$ & $\mathbf{R}^{2}$ & $\mathbf{a}$ & $\mathbf{b}$ & $\mathbf{R}^{2}$ & $\mathbf{a}$ & $\mathbf{b}$ & $\mathbf{R}^{2}$ & $\mathbf{a}$ & $\mathbf{b}$ & $\mathbf{R}^{\mathbf{2}}$ \\
\hline ATL & 4,5 & 0,5 & 0,992 & 6,5 & 0,5 & 0,989 & 22,2 & 0,4 & 0,973 & 11,4 & 0,4 & 0,983 \\
INT & 3,6 & 0,6 & 0,993 & 11,4 & 0,4 & 0,982 & 15,4 & 0,4 & 0,977 & 12,5 & 0,4 & 0,981 \\
MED & 10,8 & 0,5 & 0,985 & 12,2 & 0,4 & 0,983 & 25,4 & 0,3 & 0,970 & 22,8 & 0,4 & 0,976 \\
SBT & 13,1 & 0,5 & 0,983 & 28,1 & 0,3 & 0,968 & 7,5 & 0,3 & 0,976 & 16,3 & 0,4 & 0,978 \\
SPAIN & 12,0 & 0,5 & 0,985 & 20,7 & 0,4 & 0,976 & 30,8 & 0,3 & 0,967 & 22,8 & 0,4 & 0,976 \\
\hline
\end{tabular}




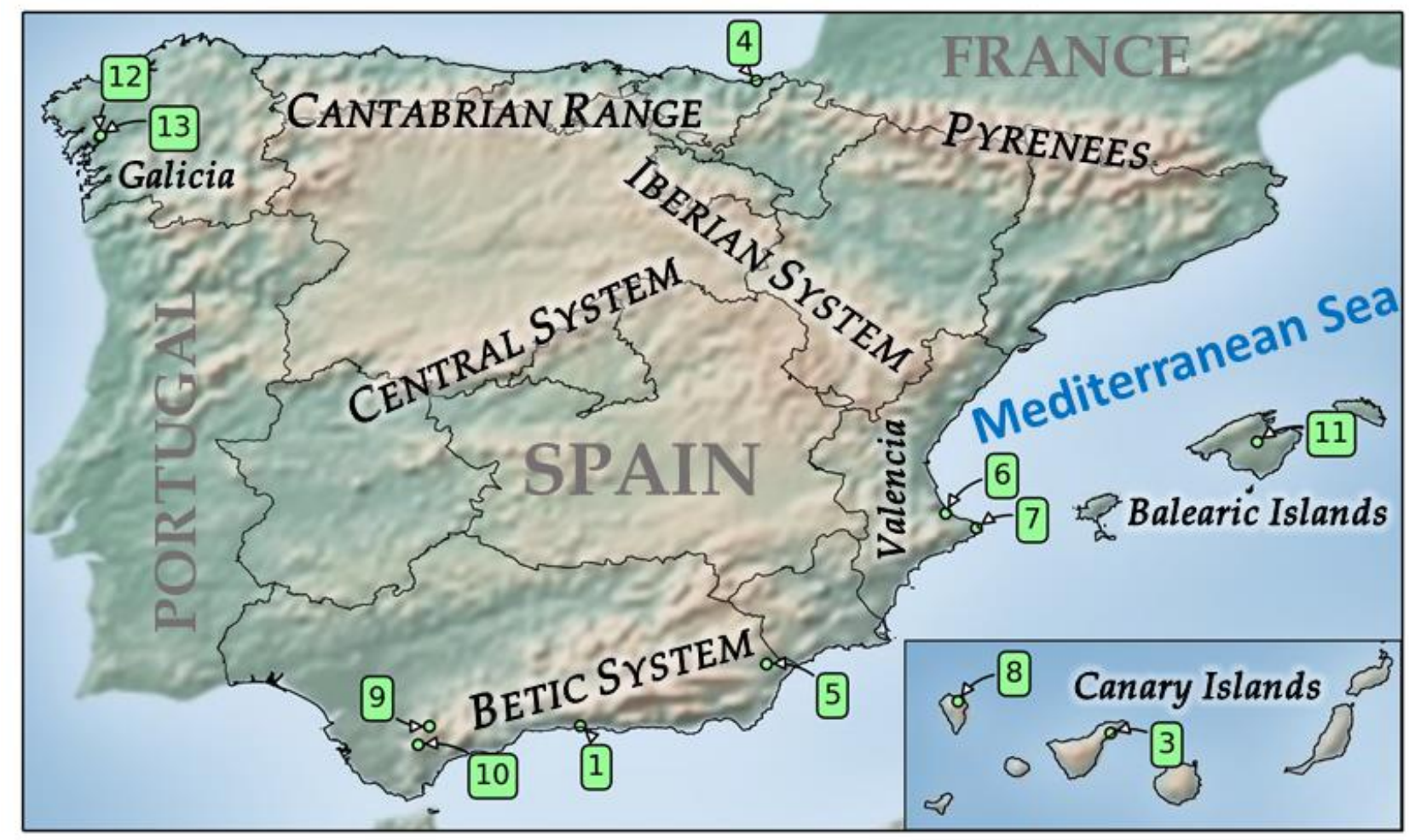

Figure 1. Geographic distribution of the SE and locations used in this study. Green numbers show the episode Id. which produced the extreme rainfall (see table 1). Lower (higher) numbers indicate shorter (larger) scales. 

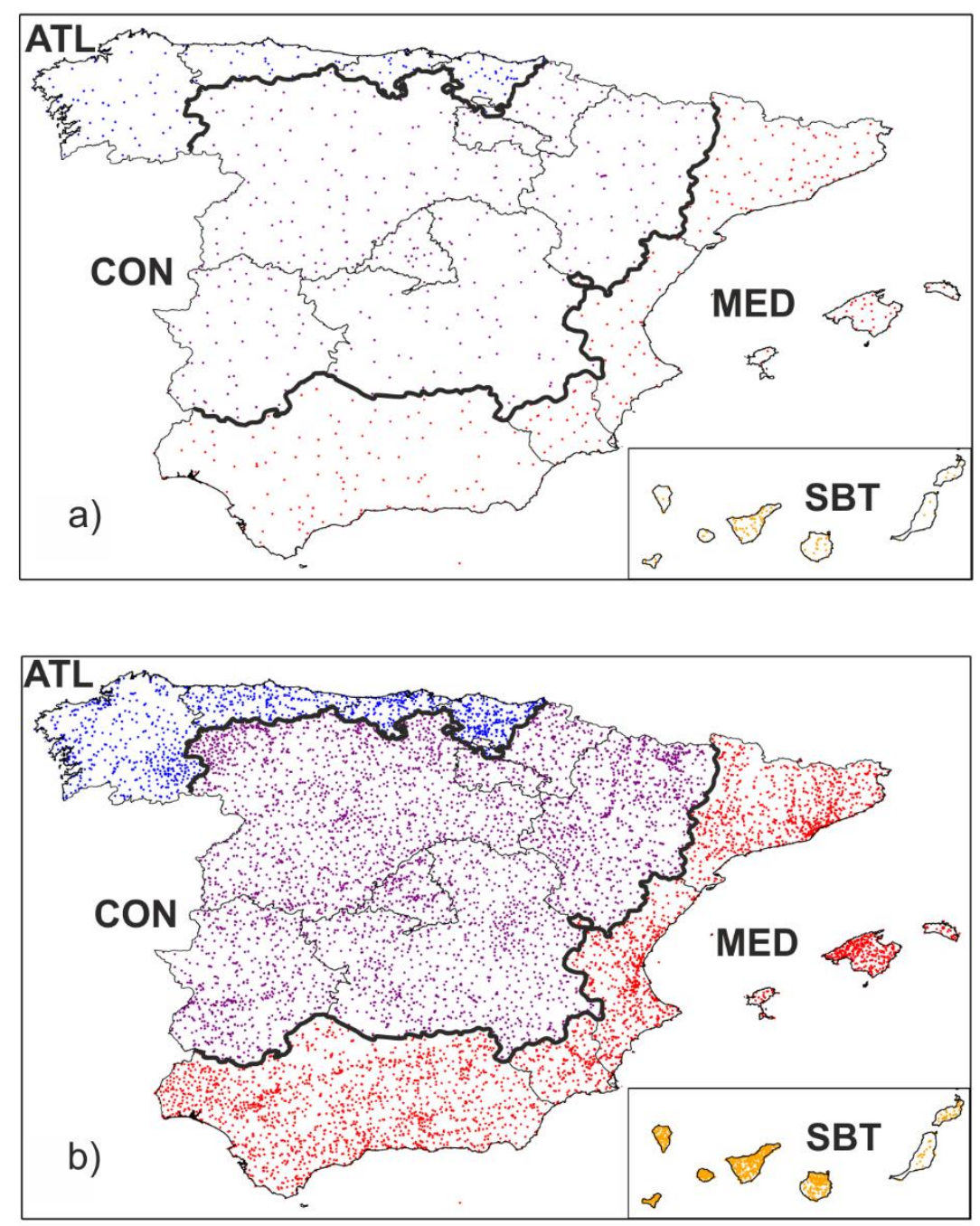

Figure 2. Sub-daily (top panel) and daily (bottom panel) database raingauge locations and regions considered in this study: Atlantic (blue), Mediterranean (red), Continental (purple) and Subtropical (orange). 


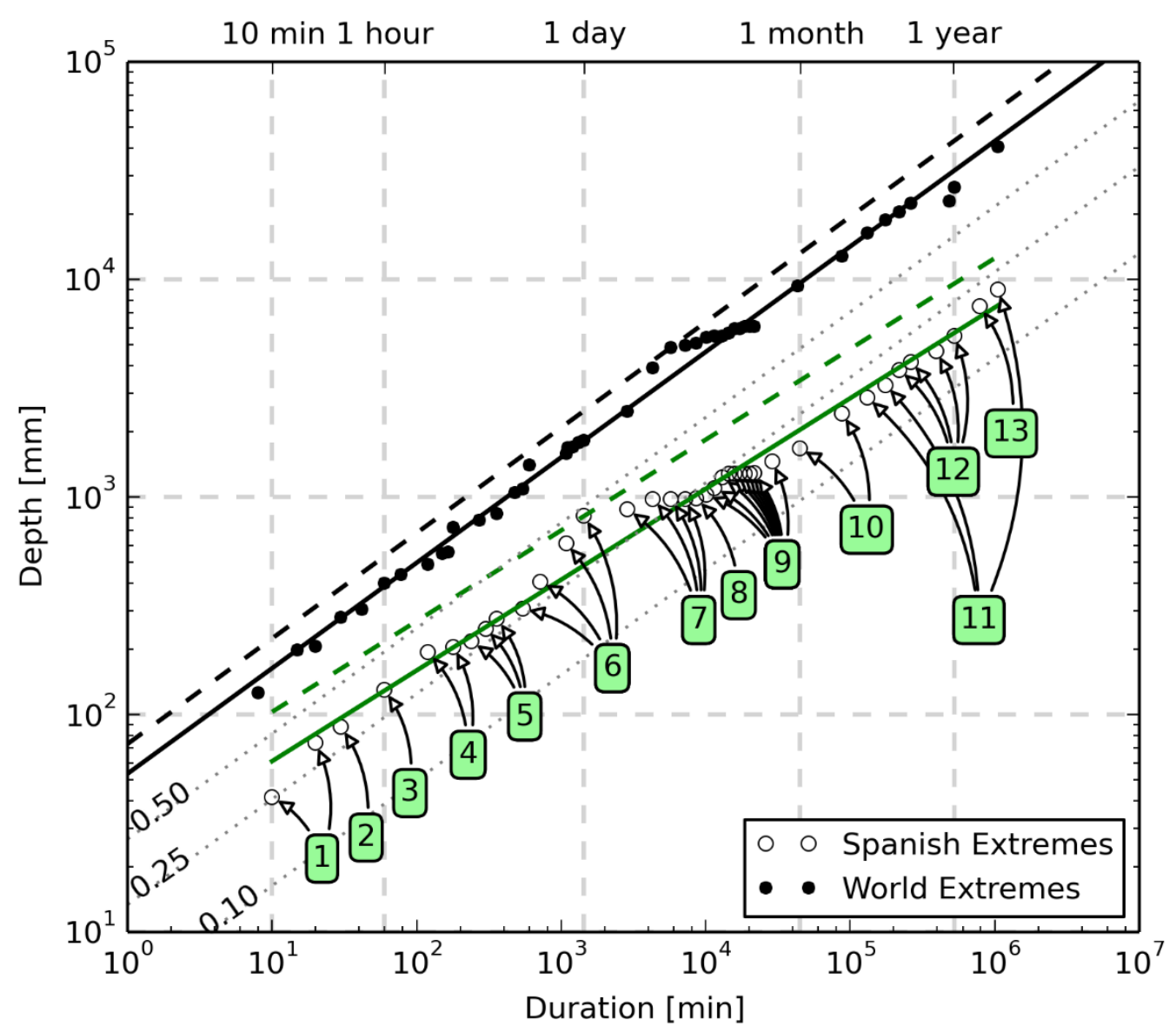

Figure 3. Observed point-based rainfall extremes for different durations for World (black dots) and Spain (green dots). Bold lines correspond to a power law fitting and dashed lines to the data upper envelope scaling. Black dotted lines show the proportion with respect to the WE fitting line as reference (i.e., 0.50 corresponds to $50 \%$ ). Numbers in green labels show the episode Id which produced the extreme rainfall (see table 1). 
a) 10 minutes

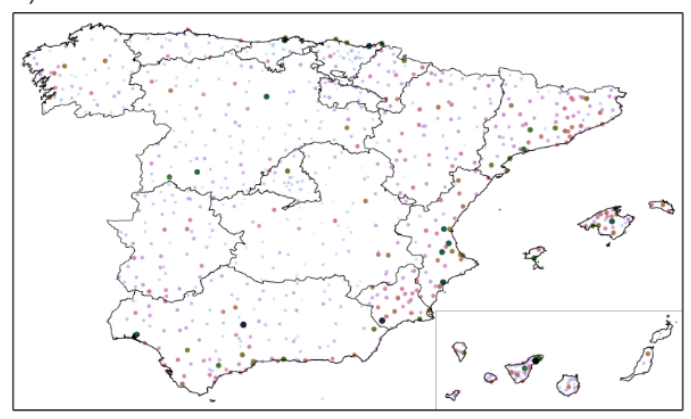

c) 1 day

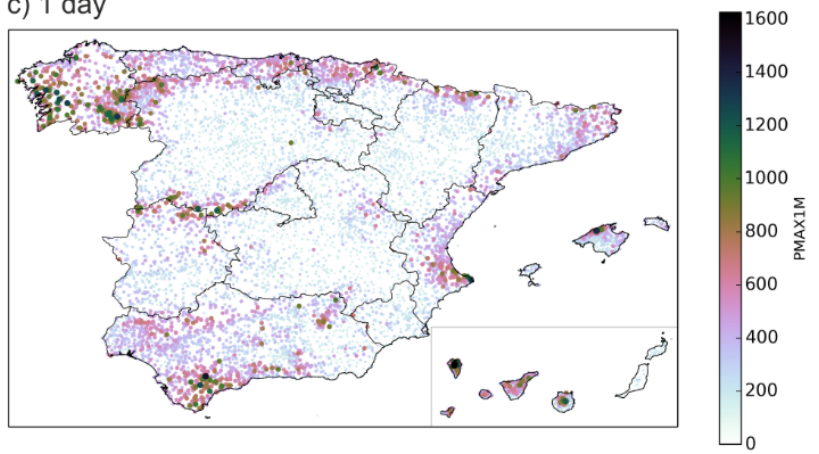

b) 60 minutes
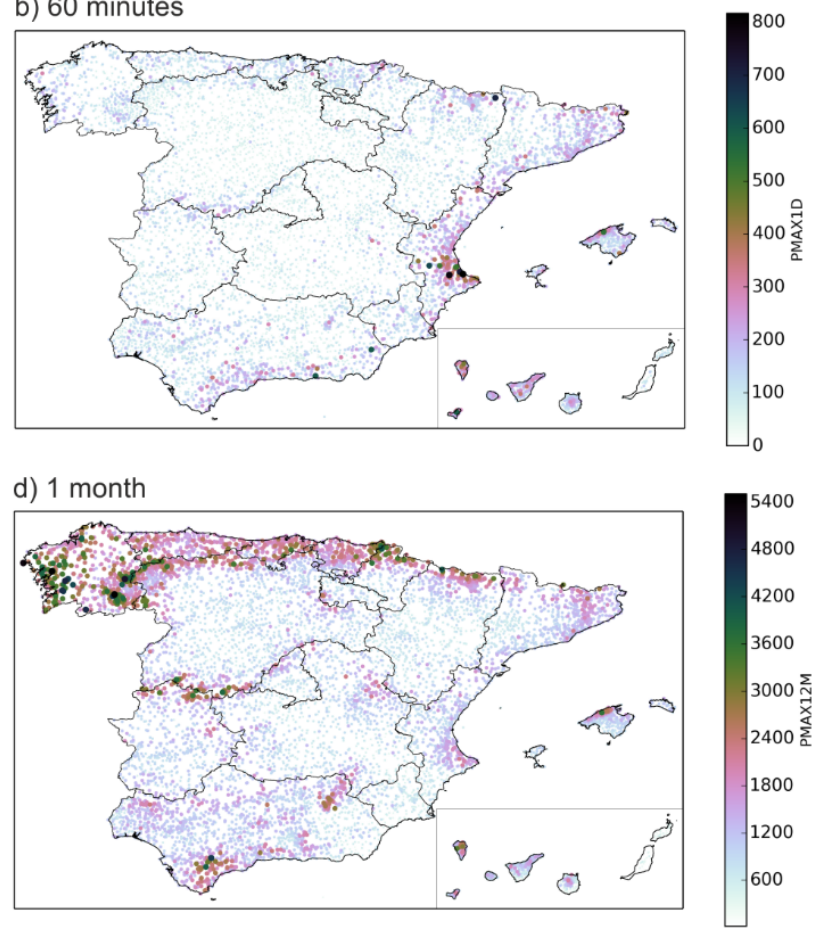

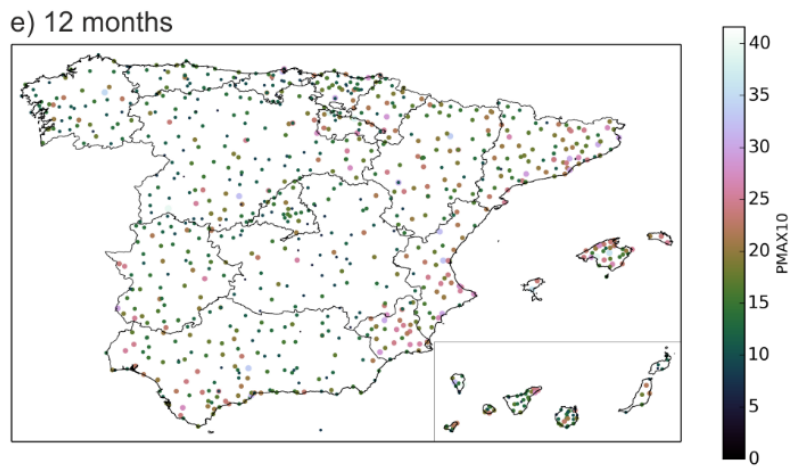

Figure 4. Extreme precipitation [mm] record maps for point-based rain gauge in Spain. Coloured points show the maximum precipitation amount recorded at each location for a) 10 minutes, b) 1 hour, c) 1 day, d) 1 month and e) 1 year. 

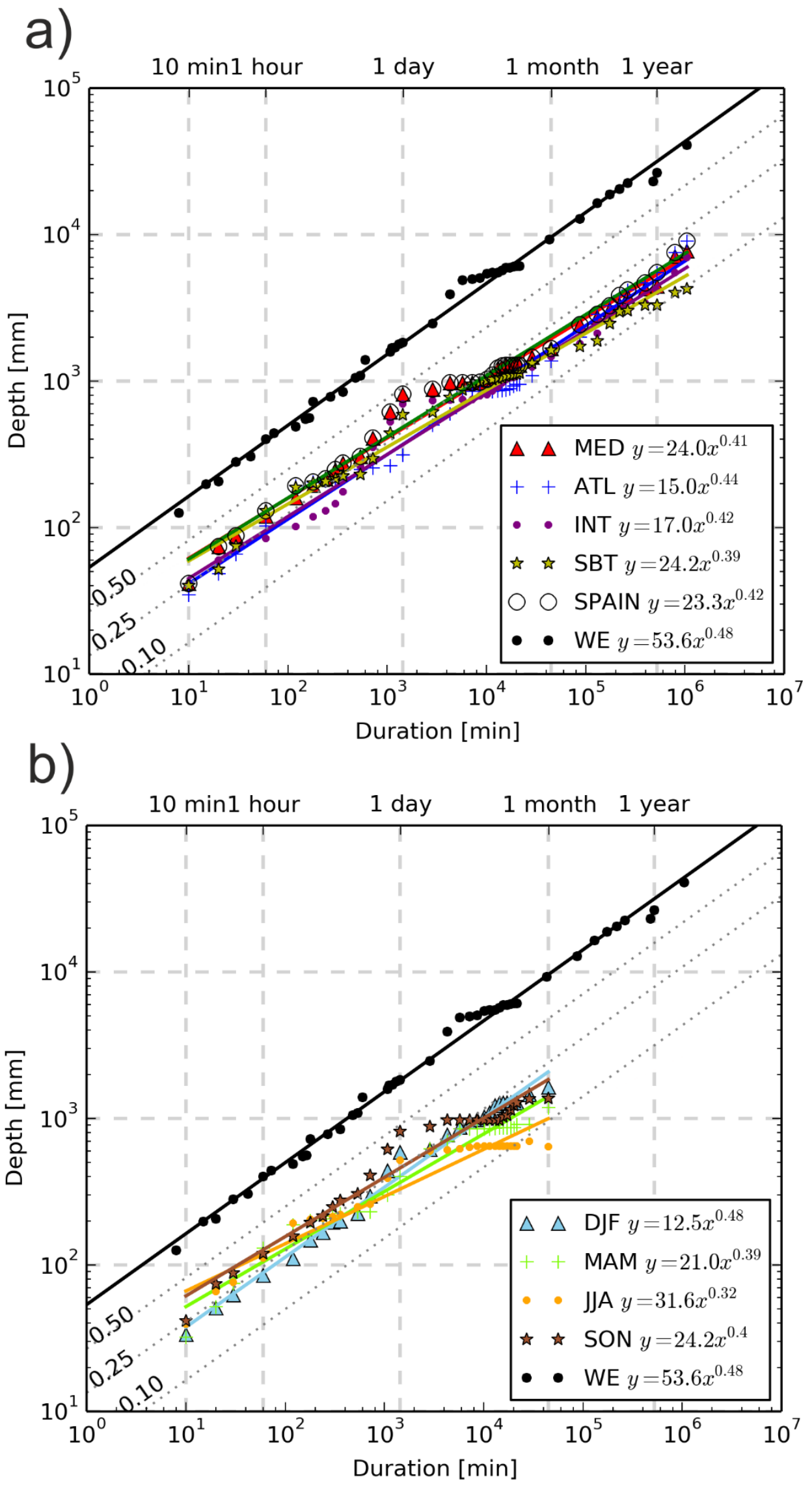

Figure 5. As Figure but showing specific records and scaling for a) each regional domain (coloured circles for each region and empty circles for all-regions record) and b) for each season for 
all-regions data. World extremes and scaling are also included for reference. 